\title{
DAMPAK PERATURAN PELARANGAN TRANSHIPMENT TERHADAP AKTIVITAS KAPAL LONGLINE DI PELABUHAN NIZAM ZACHMAN JAKARTA
}

\author{
Restu Isroq Badahi, Mercy Patanda, Hendrawan Syafrie \\ Fakultas Perikanan dan Ilmu Kelautan \\ Universitas Satya Negara Indonesia \\ E-mail: restubadahi@gmail.com
}

\begin{abstract}
Abstrak
Transhipment atau alih muat menurut Per.30/MEN-KP/2012 adalah pemindahan ikan hasil tangkapan dari kapal penangkap ikan ke kapal pengangkut ikan atau pemindahan ikan hasil tangkapan dari kapal penangkap ikan ke kapal penangkap ikan. Selanjutnya salah satu upaya mewujudkan pengelolaan sumber daya perikanan yang bertanggung jawab maka kegiatan alih muat diberhentikan. Hal ini terwujud dalam diterbitkanya Peraturan Menteri Kelautan dan Perikanan No. 57 tahun 2014.
\end{abstract}

Peraturan Menteri Kelautan dan Perikanan No. 57 tahun 2014 terbit pada tanggal 12 November tahun 2014 sebagai salah satu upaya pemerintah dalam mengatasi praktik Illegal, Unreported, dan Unregulated (IUU) Fishing yang marak dilakukan oleh pihak tidak bertanggung jawab di perairan Indonesia. Kebijakan ini berisi tentang perubahan kedua atas Peraturan Menteri Kelautan dan Perikanan No. 30 Tahun 2012 mengenai usaha perikanan tangkap di Wilayah Pengelolaan Perikanan Negara Republik Indonesia (WPPNRI) yang mengatur tentang pelarangan pendaratan ikan hasil tangkapan melalui alih muat (transhipment) di tengah laut. Perubahan dari Permen KP No. 30 Tahun 2012 yang tertuang dalam Permen KP No. 57 tahun 2014 tersebut salah satunya adalah penghapusan pasal I angka 34 yang berbunyi "Alih Muatan (Transhipment) adalah pemindahan ikan hasil tangkapan dari kapal penangkap ikan ke kapal pengangkut ikan atau pemindahan ikan hasil tangkapan dari kapal penangkap ikan ke kapal penangkap ikan". Kegiatan transhipment sebelum pelarangan, merupakan solusi untuk menekan biaya operasional akibat kenaikan harga BBM.

Transhipment diperbolehkan untuk ikan tuna segar untuk menjaga kualitas dan harga di pasar ekspor (Hamid, 2015). Namun penerapan peraturan tersebut berdampak buruk bagi pengelolaan perikanan karena ada penyimpangan oleh nelayan berupa tidak adanya pelaporan dan pencatatan hasil tangkapan (unreported and unrecorded fishing). Tidak lengkapnya laporan dan catatan data ini dapat menyebabkan terjadinya eksploitasi sumber daya ikan yang berstatus overfishing karena data hasil tangkapan jauh dari sebenarnya. Tsamenyi (2010) dalam Gustina (2014), mengatakan bahwa transhipment merupakan salah satu modus pencurian ikan. Modus transhipment artinya pemindahan suatu muatan ikan yang terjadi di tengah lautan lepas dari satu kapal ke kapal asing. Praktek transhipment seperti itu akan menyebabkan negara mengalami kerugian signifikan atas devisa dari sektor perikanan. Oleh sebab itu, Pemerintah Indonesia menyikapi kegiatan transhipment dengan menerbitkan Peraturan Perikanan yang dituangkan dalam bentuk Peraturan Menteri Kelautan dan Perikanan No. 57/PERMEN-KP/2014 tentang Perubahan Kedua atas Peraturan Menteri 
Kelautan dan Perikanan Nomor PER.30/MEN-KP/2012 Tentang Usaha Perikanan Tangkap di Wilayah Pengelolaan Perikanan Negara Republik Indonesia. Inti dari peraturan ini adalah menghentikan kegiatan alih muatan (transhipment) di laut.

\section{METODE}

Metode yang digunakan pada penelitian ini adalah metode observasi langsung dan juga pencatatan secara sistematis terhadap objek yang akan diteliti terkait data tentang hasil tangkapan ikan dan juga jumlah armada kapal longline di Pelabuhan Perikanan Samudera Nizam Zachman Jakarta. Data primer diambil dari penelitian langsung yang dilakukan di lapangan, dengan cara membagikan kuesioner masing-masing 5 responden kepada nelayan longline, dan petugas Pelabuhan Nizam Zachman Jakarta tantang dampak peraturan pelarangan transhipment. Data sekunder sebagai penunjang data primer diperoleh dari Pelabuhan Perikanan Samudera Nizam Zachman Jakarta. Data sekunder yang dikumpulkan dengan menganalisis menggunakan metode time series.

\section{HASIL DAN PEMBAHASAN}

Produksi alat tangkap longline di PPSNZJ cenderung mengalami penurunan pada periode 2014-2015 sebesar 5.572 ton. Penurunan pada tahun sebelumnya pada 2013-2014 sebelum pelarangan diberlakukan masih belum terlalu signifikan, dari 13.678,43 ton hanya mengalami penurunan sebesar 1.910,16 ton menjadi 11.768,27 ton. Penurunan pada tahun 2015 terkait dari perubahan kebijakan transhipment yang baru diterbitkan pada tanggal 12 November tahun 2014. Peningkatan hasil tangkapan longline di PPSNZJ terjadi pada tahun 2017 sebesar 1.510,3 ton. Produksi alat tangkap longline di PPSNZJ dapat dilihat pada Gambar 7.

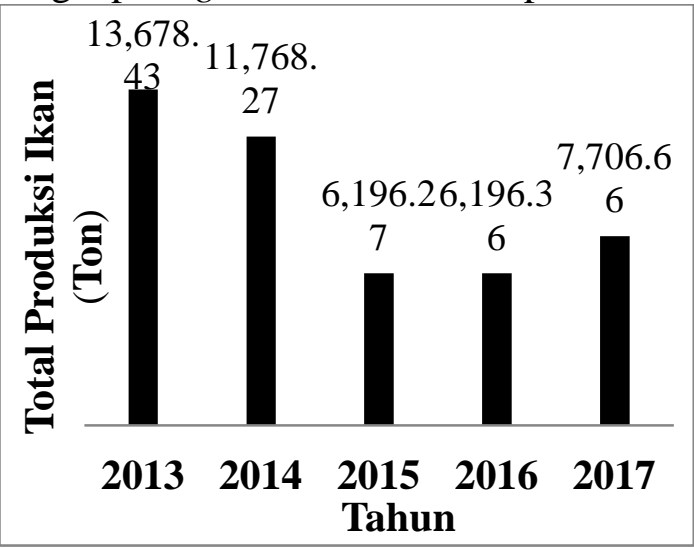

Gambar.7.

Komoditas tuna mata besar pada tahun 2014 didapatkan volume ikan sebanyak 3.496,04 ton. Pada tahun 2015 mengalami penurunan sebesar 2.307,08 ton menjadi 1.188,96 ton. Untuk komoditas tuna sirip biru pada tahun 2013 didapatkan volume ikan sebanyak 30,753 ton. Pada tahun 2015 mengalami penurunan sebesar 27,763 ton menjadi 2,99 ton. Komoditas tuna sirip kuning pada tahun 2014 didapatkan volume ikan sebanyak 3.186 ton. Pada tahun 2015 mengalami penurunan sebesar 1.950,37 ton menjadi 1.235,63 ton. Penurunan ketiga komoditas tuna yaitu pada tahun 2014-2015 terjadi akibat sedikitnya kapal yang melakukan kegiatan penangkapan dan melakukan aktivitas bongkar hasil tangkapan di Pelabuhan Perikanan Samudera Nizam Zachman Jakarta. Pada tahun 2014-2015 terjadi penurunan sebesar 206 unit kapal yang tidak melakukan kegiatan bongkar. Selain itu juga dampak lain dari diberlakukanya kebijakan transhipment terhadap armada kapal longline adalah berubahnya daerah penangkapan ikan, karena setelah perubahan kebijakan transhipment diberlakukan waktu lama kapal longline melaut semakin singkat, sehingga daerah penangkapan ikut berubah dan hasil tangkapan ikut berpengaruh. Hasil tangkapan tuna longline dapat dilihat pada Gambar 8. 


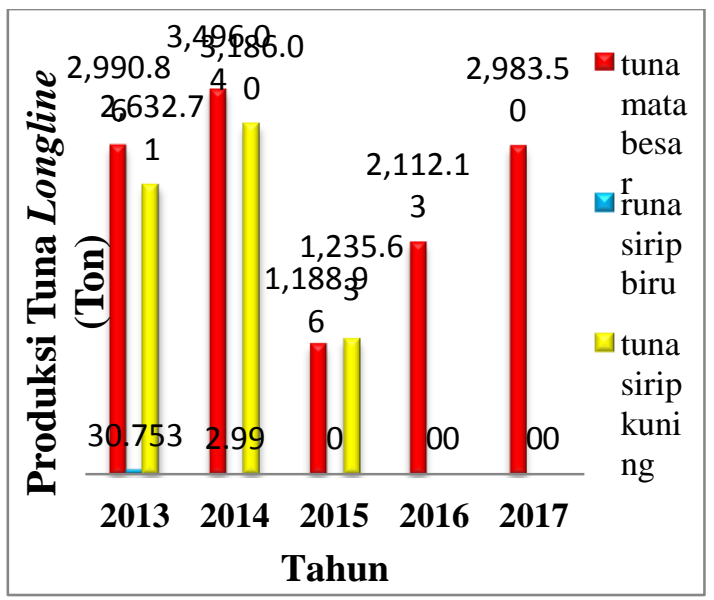

Gambar.8

Nilai produksi tuna longline sebelum pelarangan transhipment pada tahun 2013 sampai 2014 sebesar 25.446,7 ton, setelah pelarangan transhipment pada tahun 2015, 2016 dan 2017 sebesar 20.099,29 ton. Berdasarkan uji statistik jumlah produksi tuna longline sebelum kebijakan transhipment pada tahun 2013-2014 dan setelah kebijakan transhipment ditahun 2015, 2016 dan 2017 tidak berbeda nyata $(\mathrm{P}>0,05)$.

F hitung $=0,284<\mathrm{F}$ tabel $=4.30$

Hipotesa $=$ Terima H0 tolak H1

H0 : Hasil tangkapan dari tuna longline sebelum pelarangan kebijakan transhipment $>$ atau tidak berpengaruh dengan hasil tangkapan tuna longline setelah pelarangan kebijakan transhipment.

H1 : Hasil tangkapan dari tuna longline sebelum pelarangan kebijakan transhipment $<$ atau berpengaruh terhadap hasil tangkapan tuna longline setelah pelarangan kebijakan transhipment.

Jumlah perkembangan kapal longline terus mengalami penurunan dari tahun 20132017. Perkembangan kapal longline dari tahun 2013-2017 mengalami penurunan pasca pelarangan transhipment diberlakukan pada tahun 2014 Memasuki tahun 2014-2015, penurunan jumlah kapal longline ini disebabkan karena mahalnya biaya operasional yang tidak tertutupi setelah operasi penangkapan. Oleh karena itu, kapal yang biaya operasionalnya tidak balik modal hanya bersandar di pelabuhan. Perikanan longline merupakan perikanan minoritas di PPSNZJ. Kapal longline sampai tahun 2017 tercatat memiliki 161 unit kapal.

Jumlah armada yang berpangkalan di Pelabuhan Perikanan Samudera Nizam Zachman Jakarta cenderung mengalami penurunan armada 5 tahun terakhir, penurunan armada paling tinggi terjadi pada tahun 2015 dimana jumlah armada longline berkurang sebanyak 71 armada, penurunan armada di PPSNZJ pada tahun 2015 terkait dengan baru diterbitkanya kebijakan pemberhentian kegiatan transhipment pada tanggal 12 November tahun 2014.

Sedangkan pada Frekuensi kunjungan kapal di PPSNZJ periode tahun 2013-2017 menunjukan kecenderungan (trend) menurun. Jumlah kunjungan kapal di PPSNZJ mengalami penurunan pada tahun 2014, 2015 dan 2017. Sedangkan pada tahun 2016 ada kenaikan 60 kapal yang masuk ke PPSNZJ.

Dampak pertama terlihat pada berkurangnya jumlah trip bagi kapal longline. Sebelum pemberlakuan Peraturan Menteri No.57 tahun 2014 mayoritas kapal longline memiliki masa trip 6-10 bulan. Dalam kurun waktu 6-10 bulan ini mereka dapat mendaratkan ikan dengan bantuan kapal pengumpul hingga 2 sampai 3 kali untuk mengumpulkan hasil tangkapan agar tetap dalam kualitas segar, karena masa ikan tuna setelah ditangkap dari fishing ground ke darat hanya 16-18 hari paska ditangkap. Bersamaan dengan pengambilan hasil tangkapan 
oleh kapal pengumpul, kapal penangkap ikan yang berada di fishing ground pun mendapatkan tambahan perbekalan dan bahan bakar untuk melanjutkan persediaan selama melaut. Hal ini memungkinkan bertambahnya waktu operasi penangkapan pada kapal longline tanpa harus kembali kepelabuhan asal. Pengaruh peraturan kebijakan transhipment terhadap kapal longline bisa dilihat pada Tabel 3.

Tabel 3. Pengaruh Permen KP Terhadap Kinerja Kapal Longline

\begin{tabular}{|c|c|c|}
\hline \multicolumn{3}{|c|}{ Peraturan Menteri Kelautan Perikanan No 57 Tahun 2014 } \\
\hline Uraian & Sebelum Pemberlakuan & Setelah Pemberlakuan \\
\hline Jumlah trip & $\begin{array}{c}\text { Kapal diatas 50 GT rentan waktu } \\
\text { 6-10 bulan melaut dalam 1 trip }\end{array}$ & $\begin{array}{c}\text { Kapal diatas 50 GT rentang } \\
\text { waktu 2-3 bulan melaut dalam 1 } \\
\text { trip }\end{array}$ \\
\hline Produksi & $\begin{array}{c}\text { Kapal diatas 50 GT rentan palka } \\
50-70 \text { ton dapat menghasilkan } \\
100 \text { ton ikan per trip. }\end{array}$ & Hasil tangkapan sesuai palka. \\
& 10 \\
\hline
\end{tabular}

Berkurangnya jumlah trip menyebabkan dampak secara linear terhadap penurunan produksi hasil tangkapan yang di daratkan. Permintaan pasar dan tuntutan mengirim komoditas tuna dalam keadaan segar menjadi masalah ketika kebijakan larangan transhipment diberlakukan. Jika sebelumnya dengan kapal pengangkut pemilik usaha kapal longline dapat memaksimalkan umur kesegaran ikan yang tidak lebih dari 20 hari melalui penjemputan menggunakan kapal penangkapan maka sekarang kapal longline banyak memilih menyimpan tuna hasil tangkapan di palka selama melaut, sehingga harga jual akan tuna pun menurun dibandingkan dengan tuna kualitas segar yang langsung dibawa oleh kapal pengangkut.

\section{KESIMPULAN DAN SARAN}

Pengaruh penerapan kebijakan transhipment pada hasil produksi perikanan tangkap mengalami penurunan pada kurun waktu 5 tahun terakhir. Terjadi penurunan untuk total produksi tangkapan dan penurunan hasil tangkapan komoditas tuna pada alat tangkap longline.

Penurunan kinerja usaha terlihat pada berkurangnya lama trip melaut, penurunan tonase dan ukuran hasil tangkapan serta berkurangnya pendapatan akibat tidak mampu mendapatkan bonus membawa pulang hasil tangkapan penuh pada palka.

Saran.

pembuatan peraturan turunan dari Peraturan Menteri Kelautan Perikanan No. 57 Tahun 2014 tentang aturan teknis atau operasional terkait mekanisme alih muat has il tangkapan.

\section{DAFTAR PUSTAKA}

Aridja, H. L. dan Mulyanto. 1989. Pengantar Ilmu Perikanan. AUP. Jakarta

Ayodhyoa. 1981. Metode Penangkapan Ikan (Fishing Methods) Yayasan Dewi Sri. CV. Gaya Teknik. Bogor. 81 hal.

Barus, H. R., Badrudin dan N. Naamin 1991. Prosiding Forum Perikanan

Sukabumi, 18-21 Juni 1991. Pusat Penelitian dan Pengembangan Pertanian. Departemen Pertanian. Jakarta. 165-180 hal. 
Brandt, A. V. 1984. Fish Catching Methods Of The World. Fishing News (books) Ltd. London. 418 p.

Fyson J. 1985. Dasigen of Small Fishing Vessel. England Fishing News Books Ltd. 219 hal

Gustina A. 2014. Analisis Transhipment Pasal 69 ayat (3) Peraturan Menteri Kelautan Perikanan No. 30 Tahun 2012 Tentang Usaha Perikanan Tangkap. J. Dinamika Hukum. 14(2):340-349.

Jupiter H. 2000. Analisis Penurunan Produktifitas Hasil Tangkapan Ikan Tuna Segar dengan Alat Tangkap Longline di PT. Surya Sampurna Samudera, Belawan, provinsi Sumatera Utara. (skripsi). Program Studi Pemanfaatan Sumberdaya Perikanan. Fakultas Perikanan dan Ilmu Kelautan. Institut Pertanian Bogor.

Lubis, E. 2000. Pengantar Pelabuhan Perikanan (Bahan Kuliah M.A. Pelabuhan Perikanan. Laboratorium Pelabuhan Perikanan. Fakultas Perikanan dan Ilmu Kelautan. Institut Pertanian Bogor. Bogor. 71 hal.

Nomura, M dan T. Yamazaki. 1975. Fishing Techniques I. Japan Internasional Cooperation Agency. Tokyo. 184 p.

Nurani, T.W. 1996. Usaha Perikanan Longline Tuna Beku Sashimi dan Kemungkinan Pengembanganya. Program Pascasarjana. Tesis (Tidak Dipublikasikan). Fakultas Perikanan dan Ilmu Kelautan. Institut Pertanian Bogor, Bogor. 171 hal.

Nurani TW, Murdaniel RPS, Harahap MH. 2013. Upaya Penanganan Mutu Ikan Tuna Segar Hasil Tangkapan Kapal Tuna Longline untuk Tujuan Ekspor. Mar. Fish. 4(2):153-162.

Nurcholis A, Aksamalika B, Wulan N. 2015. Pengaruh Kebijakan Larangan Transhipment di Laut terhadap Ekspor Perikanan Indonesia. Bogor (ID): Institut Pertanian Bogor.

Pangemanan OVL, Mantjoro E, Jusuf Nurdin. Dampak Kebijakan Moratorium Terhadap Industri Perikanan (Studi Kasus Kota Bitung). Akulturasi-J. Ilmiah Agrobisnis Perikanan. 3(5):91-98.

PPSNZJ, 2018. Buku Statistik 2017. PPSNZJ. Kementrian Kelautan dan Perikanan.Jakarta.

Prasetyo W. 2016. Pengusaha Minta Susi Longgarkan Larangan Transhipment. Detik.com [Internet]. [diunduh 2016 April 2]. Tersedia pada: M.detik.com/Finance/Berita-EkonomiBisnis/d-3178332/Pegusaha-Mintasusi-Longgarkan-Larangan-Transhipment.

Subani, W. dan H.R. Barus. 1998. Alat Penangkapan Ikan dan Udang Laut di Indonesia. Jurnal Penelitian Peikanan Laut Edisi Khusus No. 50 Tahun 1989. Balai Penelitian Peikanan Laut. Jakarta. 212 hal.

Sugiono. 2009. Memahami Penelitian Kuantitatif. Penerbit Alfabeth. Bandung.

Sujaerweni. 2008. Belajar Mudah SPSS untuk Skripsi, Tesis, Desertasi dan Umum. Global Media Informasi. Yogyakarta. Hlm 10. 